\title{
Insulin Treatment Prevents Neuroinflammation and Neuronal Injury with Restored Neurobehavioral Function in Models of HIV/AIDS Neurodegeneration
}

\author{
@Danmeet K. Mamik, ${ }^{1}$ Eugene L. Asahchop, ${ }^{1}$ @W Wing F. Chan, ${ }^{1}$ Yu Zhu, ${ }^{1}$ William G. Branton, ${ }^{1}$ Brienne A. McKenzie, ${ }^{2}$ \\ Eric A. Cohen, ${ }^{4}$ and ${ }^{\circ}$ Christopher Power ${ }^{1,2,3}$ \\ ${ }^{1}$ Department of Medicine, ${ }^{2}$ Department of Medical Microbiology and Immunology, and ${ }^{3}$ Neuroscience and Mental Health Institute, University of Alberta, \\ Edmonton, Alberta, Canada T6G 2S2, and ${ }^{4}$ Institut de Recherches Cliniques de Montréal and Department of Microbiology, Infectiology and Immunology, \\ Université de Montréal, Montreal, Quebec, Canada H3T 1J4
}

HIV-1 infection of the brain causes the neurodegenerative syndrome HIV-associated neurocognitive disorders (HAND), for which there is no specific treatment. Herein, we investigated the actions of insulin using ex vivo and in vivo models of HAND. Increased neuroinflammatory gene expression was observed in brains from patients with HIV/AIDS. The insulin receptor was detected on both neurons and glia, but its expression was unaffected by HIV-1 infection. Insulin treatment of HIV-infected primary human microglia suppressed supernatant HIV-1 p24 levels, reduced CXCL10 and IL-6 transcript levels, and induced peroxisome proliferator-activated receptor gamma $(P P A R-\gamma)$ expression. Insulin treatment of primary human neurons prevented HIV-1 Vpr-mediated cell process retraction and death. In feline immunodeficiency virus (FIV) infected cats, daily intranasal insulin treatment (20.0 IU/200 $\mu$ l for 6 weeks) reduced CXCL10, IL-6, and FIV RNA detection in brain, although PPAR- $\gamma$ in glia was increased compared with PBS-treated $\mathrm{FIV}^{+}$control animals. These molecular changes were accompanied by diminished glial activation in cerebral cortex and white matter of insulin-treated FIV ${ }^{+}$animals, with associated preservation of cortical neurons. Neuronal counts in parietal cortex, striatum, and hippocampus were higher in the $\mathrm{FIV}^{+}$/insulin-treated group compared with the $\mathrm{FIV}^{+} / \mathrm{PBS}$-treated group. Moreover, intranasal insulin treatment improved neurobehavioral performance, including both memory and motor functions, in $\mathrm{FIV}^{+}$animals. Therefore, insulin exerted ex vivo and in vivo antiviral, anti-inflammatory, and neuroprotective effects in models of HAND, representing a new therapeutic option for patients with inflammatory or infectious neurodegenerative disorders including HAND.

Key words: FIV; HIV-1; insulin; microglia; neuropathology; neurotoxicity

Significance Statement

HIV-associated neurocognitive disorders (HAND) represent a spectrum disorder of neurocognitive dysfunctions resulting from HIV-1 infection. Although the exact mechanisms causing HAND are unknown, productive HIV-1 infection in the brain with associated neuroinflammation is a potential pathogenic mechanism resulting in neuronal damage and death. We report that, in HIV-infected microglia cultures, insulin treatment led to reduced viral replication and inflammatory gene expression. In addition, intranasal insulin treatment of experimentally feline immunodeficiency virus-infected animals resulted in improved motor and memory performances. We show that insulin restored expression of the nuclear receptor peroxisome proliferator-activated receptor gamma (PPAR- $\gamma$ ), which is suppressed by HIV-1 replication. Our findings indicate a unique function for insulin in improving neurological outcomes in lentiviral infections, implicating insulin as a therapeutic intervention for HAND.

\section{Introduction}

All lentiviruses infect glial cells in the nervous system, frequently resulting in devastating neurological diseases (Power and Johnson,
2001). The immunodeficiency-associated lentiviruses, including human (HIV), simian (SIV), and feline (FIV), are especially recognized for their capacity to cause immunosuppression and eventual 
brain disease (Clements et al., 1994; Shen et al., 2007). Lentivirusmediated neurodegeneration is driven by viral protein effects accompanied by proximal inflammation in the nervous system with ensuing neuronal damage or death that manifests as neurobehavioral abnormalities (Gonzalez-Scarano and Martin-Garcia, 2005). The memory, motor, and behavioral deficits caused by HIV-1 infection fall within the spectrum syndrome termed HIV-associated neurocognitive disorders (HAND). Despite available modern antiretroviral therapy (ART), patients with HAND represent $25-30 \%$ of the HIV/AIDS population (Nightingale et al., 2014), report poorer quality of life, and show reduced survival compared with HIV/AIDS patients without neurological disease (McArthur et al., 2010; Vivithanaporn et al., 2010; Heaton et al., 2011; Nakagawa et al., 2015). There are currently no specific treatments for HAND. Modern ART regimens show inconsistent effects on neurocognitive performance and some ARTs have been associated with neurotoxic effects and worsened neuropsychological outcomes (Meeker et al., 2014).

The precise determinants of HAND remain unclear, although host factors (age, genetic background, comorbidities), neuroinflammatory processes (inflammasome activation, cytokine production), and viral properties (replicative capacity, neural cell tropism and virus-encoded neurotoxic proteins) have been implicated in its pathogenesis (Gannon et al., 2011; Schnell et al., 2011). As the population with HIV/AIDS ages, the likelihood of comorbid metabolic disorders is rising, with increased risks of type 2 diabetes mellitus (T2DM), stroke, hypertension, and hyperlipidemia that can be exacerbated by ART. In fact, T2DM is an established risk factor for HAND and, interestingly, is also associated with the development of Alzheimer's disease (Barbagallo and Dominguez, 2014). Insulin resistance has broad systemic effects, although the evidence for insulin resistance in the brain awaits clarification (Derakhshan and Toth, 2013). Antiglycemic drugs suppress HIV-1 replication in cultured leukocytes and in models of HAND, possibly through a mechanism by which peroxisome proliferator-activated receptor gamma (PPAR- $\gamma$ ) expression and its effects were potentiated (Potula et al., 2008). Concurrent with these observations, shedding of the insulin receptor (IR) in plasma and CSF is a feature of HAND (Gerena et al., 2012; Suh et al., 2015). Finally, the insulin-like growth factor II/mannose 6 phosphate receptor (M6PR) has been proposed recently as a receptor for HIV-1 gp120 (Dohgu et al., 2012). These reports provide evidence for aberrant IR function in HAND pathogenesis.

FIV is closely related to HIV-1 and SIV in terms of genomic structure and pathogenic properties (Olmsted et al., 1989; Torten et al., 1991; Kolenda-Roberts et al., 2007). FIV infects lymphocytes (Brown et al., 1991), macrophages (Brunner and Pedersen, 1989) as well as microglia in the brain causing immunodeficiency and neurological disease in domestic cats (Johnston et al., 2002). We have previously shown that FIV infection of the brain is dependent on macrophage/microglial infection and results in a specific neurological phenotype caused by neuroinflammation and neuronal loss (Power et al., 1998a; Maingat et al., 2009). FIVmediated neurological deficits are evident as impaired motor and neurocognitive functions occasionally accompanied by seizures and agitated behaviors, thus recapitulating many of the clinical features observed in HAND (Fletcher et al., 2008). We showed previously that treatment of FIV-infected cats with growth hormone induced insulin-like growth factor-1 (IGF-1), improved neurobehavioral performance, and reduced neuroinflammation (van Marle et al., 2005). Similarly, growth hormone improved neurocognitive performance in patients with HAND and pro- tected neurons from virus-mediated cytotoxicity (Silva et al., 2003).

Because insulin and IGF-1 can act through each other's cognate receptors, we investigated the effects of insulin treatment in models of HAND. We observed that HIV-1 and FIV infections resulted in activation of inflammatory genes in microglia and neuronal injury, which were prevented by insulin treatment with associated suppression of viral replication. These findings were reinforced by improved in vivo neuropathological and neurobehavioral outcomes.

\section{Materials and Methods}

Experimental design. The study was designed to test the hypothesis that insulin regulates $\mathrm{HIV}-1$ replication and associated neuroinflammation in the brain and that intranasal insulin treatment in an HIV/AIDS animal model is neuroprotective. Primary human microglia and neurons were used for the ex vivo studies. An established FIV model of HAND was used for the in vivo studies. All breeders were outbred and five independent litters from different breeding animals were used for the in vivo studies to eliminate any possible litter-biased outcomes. Sample size for in vivo animal experiments was based on the available litter.

Ethics statement. The use of autopsied brain tissues (protocol number 2291) was approved by the University of Alberta Human Research Ethics Board (Biomedical) and written informed consents were signed before or at the time of tissue collection. The protocols for obtaining postmortem brain samples comply with all federal and institutional guidelines with special respect for the confidentiality of the donor's identity. Human fetal tissues were obtained with informed consent from the donors approved under the protocol number 1420 by the University of Alberta Human Research Ethics Board (Biomedical). All animal experiments were performed according to Canadian Council on Animal Care (http://www. ccac.ca/en) and were approved by the University of Alberta Animal Care Committee. The experiments involving FIV infection of cats were part of ongoing approved studies (protocol number 449).

Tissues. Human fetal tissues were obtained from 15- to 22-week-old elective abortions, as described previously (Power et al., 1998b; Walsh et al., 2014). Briefly, neural cells were isolated and maintained in MEM/10\%FBS medium supplemented with $1 \%$ sodium pyruvate, $1 \%$ glutamine, $1 \%$ nonessential amino acids, $0.1 \%$ dextrose, penicillin/streptomycin, and gentamicin (Na et al., 2011). Human fetal microglia (HFM) were prepared, followed by HIV-1 infection 1-2 d after preparation of cultures. Supernatants and cells were collected in TRIzol (cells only) at $5 \mathrm{~d}$ after infection. Human fetal neurons were cultured in medium containing cytosine arabinoside and used within 2 weeks of culture (Walsh et al., 2014). Human brain (frontal lobe) was collected at autopsy with consent and frozen at $-80^{\circ} \mathrm{C}$ or fixed in formalin (10\%) from patients with HIV/AIDS (HIV encephalitis, $n=4$; normal brain $n=2$; median age, 42 years; male:female, 4:2; none receiving ART at death) or from patients with non-HIV/AIDS disorders (sepsis, $n=3$; cancer, $n=2$; myocardial infarction, $n=1$; median age, 45 years; male:female, 3:3) (Vergote et al., 2006; Noorbakhsh et al., 2010).

Cells and reagents. Human peripheral blood mononuclear cells (PBMCs) were isolated from the blood of healthy subjects by Histopaque 1077 (Sigma-Aldrich) purification (Johnston and Power, 1999). Peripheral blood lymphocytes (PBLs) were then negatively selected from PBMCs by plastic adherence properties of monocytes and monocytederived cells. Human PBLs were maintained in RPMI/15\% FBS with phytohemagglutinin-M (PHA-M) stimulation for $3 \mathrm{~d}$, after which time cells were stimulated with human interleukin-2 (IL-2) and then mock or HIV infected. Feline lymphocytic cells (MYA-1) were stimulated with human IL-2 and maintained in RPMI/15\% FBS. Cells were infected with HIV-1 or FIV with a multiplicity of infection (MOI) of 0.05-0.1. After $4 \mathrm{~h}$, input virus was washed off and fresh medium added. Supernatants and cell suspensions were collected on days 1 (24 h), 5 (d5), 7 (d7), and 10 (d10) after infection.

Viruses, HIV-1 p24 ELISA, and reverse transcriptase assay. Infectious $\mathrm{HIV}-1_{\mathrm{YU} 2}$ was produced by transfection of $16 \mu \mathrm{g}$ of the full-length HIV-1 YU-2 plasmid DNA into HEK293 T cells using Lipofectamine 2000 (Invitrogen). After $48 \mathrm{~h}$, supernatants were collected, centrifuged at $500 \times g$ 
Table 1. Oligonucleotide primers used in real-time PCR analyses

\begin{tabular}{|c|c|c|c|}
\hline Gene & Species & Sequence (F) & Sequence $(R)$ \\
\hline HLA-DQ1 & Human & $5^{\prime}$-GGT GTA AAC TTG TAC CAG-3' & 5'-ATT GGT AGC AGC AGT AGA-3' \\
\hline IL-6 & Human/feline & 5'-GGT ACA TCC TCG ACG GCA TCT-3' & 5'-GTG CCT CTT TGC TGC TTT CAC-3ל \\
\hline PPAR $\gamma$ & Human & $5^{\prime}$-TAC TGT CGG TTT CAG AAA TGC C-3' & 5'-GTC AGC GGA CTC TGG ATT CAG-3' \\
\hline IR & Human & 5'-CGT GGT CCT TTG GGA AAT CA-3' & 5'-GTT GTC GGG TTG ATC CAG ATA C-3' \\
\hline IGF-1R & Human & $5^{\prime}$-CAT GGT GGA GAA CGA CCA TAT C-3' & 5'-GAG GAG TTC GAT GCT GAA AGA A-3' \\
\hline$I L-1 \beta$ & Human/feline & $5^{\prime}$-CAA CCA ACA AGT GAT ATT CTC C-3' & $5^{\prime}$-GAT CCA CAC TCT CCA GCT GCA-3' \\
\hline MX1 & Human & $5^{\prime}$-CGG GGA AGG AAT GGG AAT CAG TCA-3' & $5^{\prime}$-TTC CGC ACC ACG TCC ACA ACC TT-3' \\
\hline FIV-pol & Feline & 5'-ACC TAC TTC TAG AGA AGC CTG-3' & 5' -GTA TCT GTC CAA TAG GCT GC-3' \\
\hline HIV-pol & Human & $5^{\prime}$-TTA AGA CAG CAG TAC AAA TGG CAG T-3' & 5' -ACT GCC CCT TCA CCT TTC CA-3' \\
\hline GAPDH & Human/feline & 5'-AGC CTT CTC CAT GGT GGT GAA-3' & $5^{\prime}$-CGG AGT CAA CGG ATT TGG TCG-3' \\
\hline
\end{tabular}

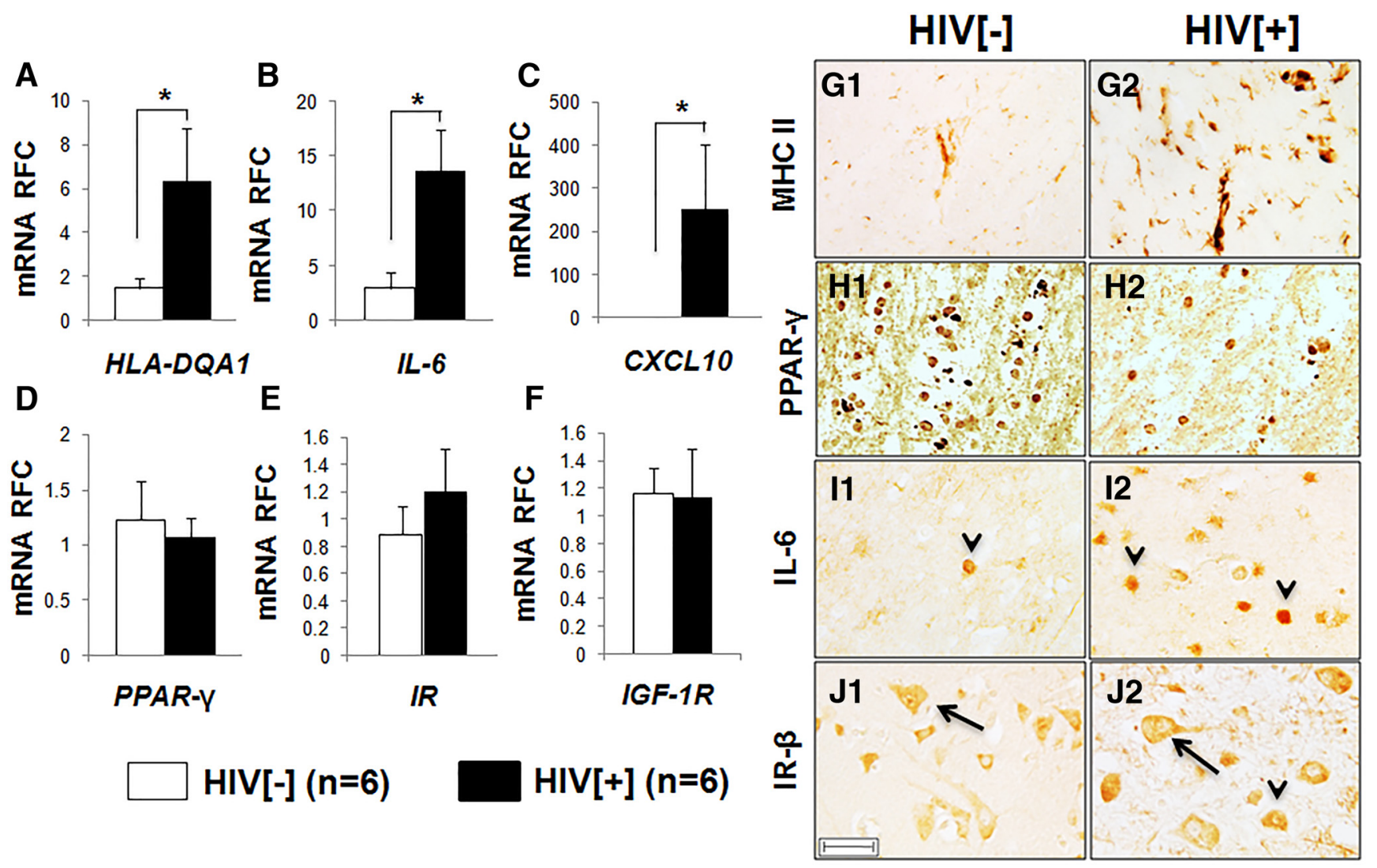

Figure 1. Expression of proinflammatory genes in HIV-infected human brain white matter. Analyses of transcript levels in frontal white matter disclosed that $H L A-D Q A 1$ (A), IL-6 (B), and $C X C L 10$ $(\boldsymbol{C})$ were increased in the $\mathrm{HIV}^{+}$group, whereas PPAR- $\gamma(\boldsymbol{D}), I R(\boldsymbol{E})$, and IGF- $\mathrm{IR}(\boldsymbol{F})$ were similar in HIV-1-infected samples $\left(\mathrm{HIV}^{+}, n=6\right)$ compared with uninfected control samples (HIV ${ }^{-}, n=$ 6), as measured by real-time PCR normalized to GAPDH and expressed as relative fold change (RFC). Immunohistochemical detection in $\mathrm{HIV}^{+}$and HIV ${ }^{-}$frontal lobe brain sections showed that MHC Class II on macrophages/microglia $(\boldsymbol{G})$ and IL- 6 on glia $(\boldsymbol{H})$ were increased in HIV ${ }^{+}$brain sections, but PPAR- $\gamma(\boldsymbol{I})$, detected in glial cytoplasm and nuclei, was reduced in HIV ${ }^{+}$sections, whereas IR- $\beta$ immunoreactivity $(\boldsymbol{J})$, detected on neurons and glia, was similar in $\mathrm{HIV}^{-}$and $\mathrm{HIV}^{+}$brain sections. Data represent mean \pm SEM (Student's $t$ test, ${ }^{*} p<0.05$ ). Original magnification, 200X; scale bar, $20 \mu \mathrm{m}$.

for $10 \mathrm{~min}$, and filtered through $0.45 \mu \mathrm{m}$ filters (Millipore). HIV-1 p24 concentrations in the culture supernatants and viral stocks were quantified by ELISA according to the manufacturer's protocol (Advanced Bioscience Laboratories). Reverse transcriptase activity was assayed according to the manufacturer's protocol (InnovaGen). Viral production was measured in supernatants from feline MYA-1 $\mathrm{T}$ cells infected with the neurovirulent molecular FIV chimeric clone $\left(\mathrm{FIV}_{\mathrm{ch}}\right)$ $(\mathrm{MOI}=0.1)$ (Johnston et al., 2002); human PBMCs or microglia were infected with HIV-1 $1_{\mathrm{YU} 2}(\mathrm{MOI}=0.1)$. Culture supernatants from human PBMCs infected with HIV-1 $1_{\mathrm{YU} 2}$ with known p24 levels were used for $e x$ vivo infection experiments of HFM. All ex vivo experiments were performed using primary cells from at least three different donors.

Neurotoxicity assay. Primary human neurons were exposed to recombinant baculovirus-derived Vpr (Kinnakeet Biotechnology) with or without insulin pretreatment $(1 \mathrm{~h} ; 0.1-3 \mathrm{IU} / \mathrm{ml})$. At $48 \mathrm{~h}$, cells were fixed, blocked, and incubated with primary an anti- $\beta$ III-tubulin antibody (SigmaAldrich). After primary antibody application, the cells were washed in PBS containing $0.1 \%$ Tween 20 and incubated with donkey anti-mouse IRDye 800CW (1:800 dilution; Rockland Immunochemicals) secondary antibodies. After removal of the secondary antibodies, the cells were washed in PBS/ $0.1 \%$ Tween 20 and left to dry in the dark before quantification of $\beta$ IIItubulin expression using the Odyssey Infrared Imaging System (LI-COR). Results are expressed as the percentage of $\beta$ III-tubulin expression in control neurons. To quantify neuronal survival, cell cultures in 96-well plates were incubated with DAPI (ImmunoChemistry Technologies) for 5-10 min, followed by washing with PBS. Plates were read at $360 \mathrm{~nm}$ with wavelength correction at $460 \mathrm{~nm}$ using a microplate reader (Synergy HT; Biotek Instruments; $\mathrm{Na}$ et al., 2011).

Animal experiments. Adult pregnant cats (queens) were housed in the University of Alberta animal care facility and maintained according to 
the Canadian Committee of Animal Care guidelines. Queens were negative for feline retroviruses [FIV and feline leukemia virus (FeLV)] by PCR analysis and serologic testing. Animals were injected intracranially (right parietal lobe) one day postpartum with $200 \mu \mathrm{l}$ of virus $\left(10^{4} \mathrm{TCID}_{50} / \mathrm{ml} ; \mathrm{FIV}_{\mathrm{ch}}\right.$ or mockinfected) using a 30 gauge needle (Maingat et al., 2009). FIV-infected ( $\mathrm{FIV}^{+}$) and mockinfected $\left(\mathrm{FIV}^{-}\right.$) animals were monitored for 12 weeks after infection. Neurobehavioral tests were performed and blood samples were collected during this period. Animals were killed by pentobarbital overdose at 12 weeks after infection. Brain (right hemisphere) was collected and snap frozen at $-80^{\circ} \mathrm{C}$ for subsequent total RNA or protein extractions. The left hemisphere of the brain was fixed in $4 \%$ buffered paraformaldehyde, $\mathrm{pH}$ 7.4, for histochemical and immunocytochemical analyses. Animals were treated $5 \mathrm{~d} /$ week beginning at week 6 after infection with intranasal insulin (Novolin R; Novo Nordisk) at concentration of $20 \mathrm{IU}$ in $200 \mu \mathrm{l}$ total volume or PBS as a vehicle control, which were delivered by a syringe-driven nebulizer into each nostril from 6-12 weeks after infection.

Real-time PCR. Host and viral gene expression were measured by real-time $\mathrm{qPCR}$ as reported previously (Maingat et al., 2009; $\mathrm{Na}$ et al., 2011). Human (frontal white matter) and feline (parietal cortex and striatum) tissues or cultured cells were suspended in TRIzol reagent (Invitrogen) and then homogenized using a Fast-Prep-24 tissue homogenizer (MP Biomedicals). RNA was extracted using choloroform:isoamyl alcohol and purified using an RNeasy Purification Kit (Qiagen). cDNA from tissue samples was synthesized from $1 \mu \mathrm{g}$ RNA using random oligonucleotide primers (Table 1; Roche). Ex vivo cell culture samples solubilized in TRIzol reagent were prepared similarly except RNA template used for cDNA synthesis ranged from $300 \mathrm{ng}$ to $1 \mu \mathrm{g}$ per sample based on minimum yield. All samples were analyzed by real-time PCR on a MyiQ thermocycler (Bio-Rad). Threshold cycle values for each gene were normalized to gapdh and are represented as average relative fold change compared with control.

Droplet digital PCR (ddPCR). Diluted cDNA preparation from feline brain-derived RNA was mixed with FIV pol primers (900 nM): forward 5'ATGGAGGTAGAAAGCTAGGAAAAG-3'; reverse 5' -TGCCTTCTGAT TACTGCCTTC-3'; and probe (250 nm): 5'-ACAGATACAGGAAAGTG GCAAGTGATGG-3' and ddPCR Supermix for Probes (Bio-Rad). The reaction mixture was emulsified with droplet generation oil (Bio-Rad) using a QX200 droplet generator according to the manufacturer's protocol. The droplets were transferred into a 96-well plate (Eppendorf) and heat-sealed with pierceable foil (Bio-Rad). PCR was performed in a Bio-Rad S1000 Thermal Cycler with the following cycling conditions: $10 \mathrm{~min}$ at $95^{\circ} \mathrm{C}, 40$ cycles of $30 \mathrm{~s}$ at $94^{\circ} \mathrm{C}$, followed by $1 \mathrm{~min}$ at $60^{\circ} \mathrm{C}$ and a final $10 \mathrm{~min}$ at $98^{\circ} \mathrm{C}$. The 96 -well plate was transferred to a QX200 Droplet Reader (Bio-Rad) and the presence of positive droplets and the resulting total copy number per reaction were quantified and calculated by the manufacturer's QuantaSoft software.

Flow cytometry and serum glucose levels. Feline PBMCs were isolated from the blood of $\mathrm{FIV}^{-}$and $\mathrm{FIV}^{+}$animals at 8 and 12 weeks after infection. Mouse anti-feline CD4 antibodies used for flow cytometry were acquired from Dr. Peter Moore (University of California-San Diego). PBMCs were immunolabeled with mouse anti-feline CD4 antibodies followed by goat anti-mouse IgG conjugated to FITC. PBMCs labeled with secondary antibody alone served as control. Flow cytometry was performed using a FACSCanto II (BD Biosciences) and data were analyzed using FACSDiva and FlowJo software. In pilot studies of FIV ${ }^{-}$animals $(n=3)$, blood glucose levels were measured at 15 and 90 min after intranasal insulin treatment using a veterinary blood glucose monitor.

Neurobehavioral assessment. Neurobehavioral parameters in 12-week $\mathrm{FIV}^{-}(n=6), \mathrm{FIV}^{+}$, and insulin-treated $\mathrm{FIV}^{+}(n=6)$ animals were evaluated at 12 weeks after infection. Locomotor function was determined by analyzing the inked footprints formed by cats walking across a suspended plank. Distance between the right and left paw placement was measured and the variance in gait width calculated. Spatial memory and cognitive ability was measured using a modified T-maze. The number of errors and time to completion of the maze were recorded. The object-memory test was used to measure spatial and object memory (Maingat et al., 2009). Animals were required to step over a $6 \mathrm{~cm}$ moveable barrier with their forelimbs to reach a food reward. Subsequently, the barrier was withdrawn without the animal's knowledge. The animal's ability to recall the height and position of the barrier was monitored by tracking the trajectory of the hindlimb though the space occupied by the barrier as it followed the food reward. Tracking the trajectory was accomplished using reflective dots placed on the outside of the animals' hindlimb. Animal performance was recorded on film. Successful attempts were counted and recorded as a percentage of total (Polyak et al., 2013).

Immunohistochemistry. Immunohistochemistry of human and feline brain sections was performed as described previously (Maingat et al., 2009). Briefly, human and feline paraformaldehyde-fixed, paraffinembedded brain tissue sections were mounted onto slides. Slides were rehydrated using a xylene-ethanol series, followed by antigen retrieval using $10 \mathrm{~mm}$ sodium citrate buffer, $\mathrm{pH}$ 6.0, and then immunostained with the antibodies anti-ionized calcium binding adaptor molecule 1 

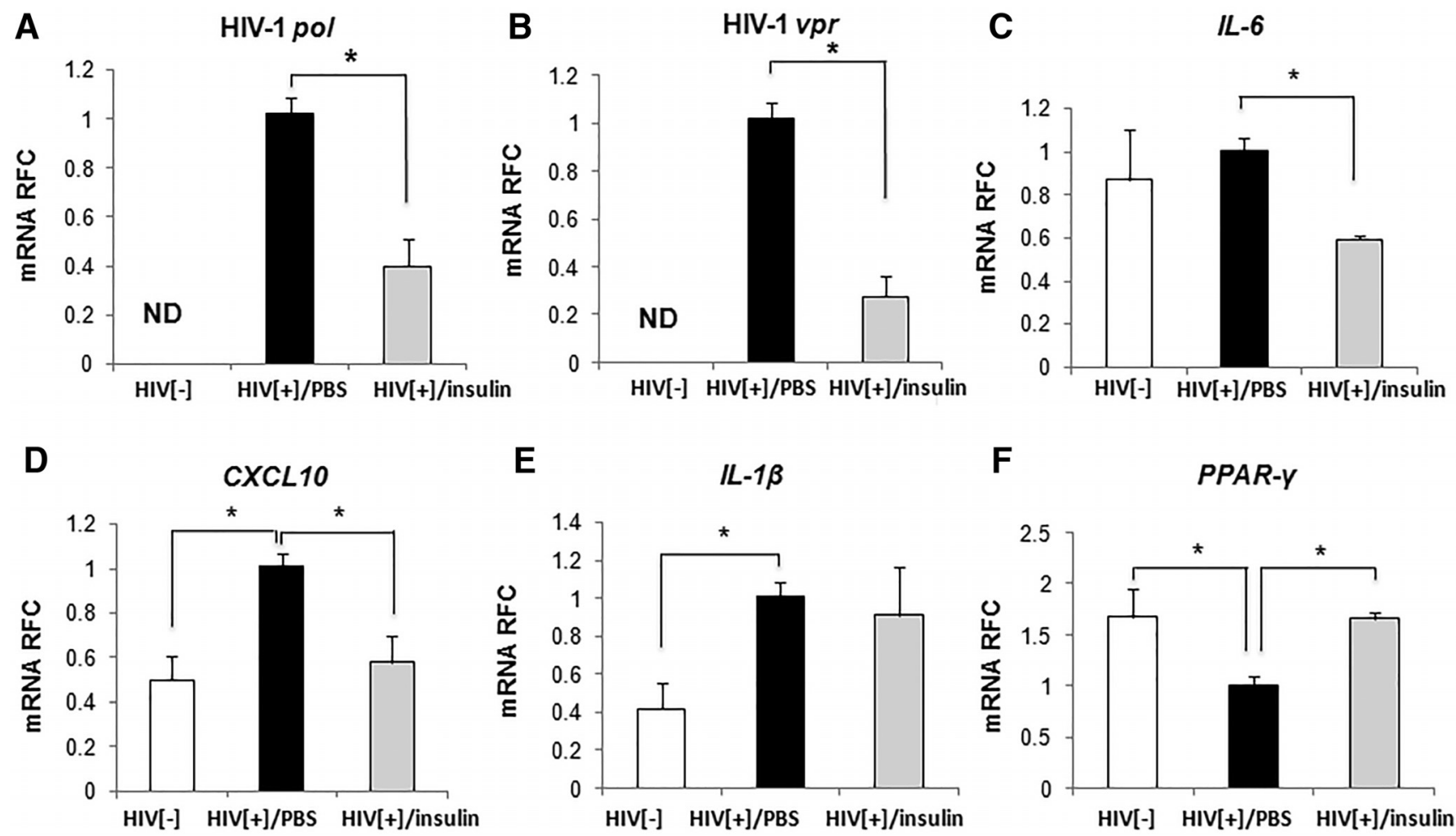

Figure 3. Expression of proinflammatory and viral genes in HIV-infected human microglia treated with insulin. Primary human microglia were infected with HIV-1 $\mathbf{Y}_{\mathrm{YU2}}$, $\mathrm{followed}_{\mathrm{B}}$ by insulin treatment (1.0 IU/ml). Analyses of expression revealed that insulin treatment suppressed HIV pol $(\boldsymbol{A}), \mathrm{HIV} v \operatorname{vpr}(\boldsymbol{B}), \boldsymbol{l} L-6(\boldsymbol{C})$, and $C X C L 10(\boldsymbol{D})$, but not $/ L-1 \beta(\boldsymbol{E})$, whereas insulin treatment $(\boldsymbol{F})$ increased PPAR- $\gamma$ expression in HIV-infected microglia measured in real-time PCR (day 5 after infection). Data represent mean \pm SEM with a minimum of three replicates per group (one-way ANOVA, post hoc Tukey's test, $\left.{ }^{*} p<0.05\right)$.

(Iba1; Wako), anti-FIV gag-pol (Custom Monoclonals International), anti-IL-6 (BD Biosciences), anti-IR $\beta$ and anti-PPAR- $\gamma$ (Abcam), antiMHC Class II (Dako), and anti-MAP-2 (Sigma-Aldrich) at a 1:100 dilution. Immunoreactivity was detected using 3,3'-diaminobenzidine tetrachloride (DAB; brown; Vector Laboratories) and then dehydrated and mounted in Acrytol (Leica Microsystems). Slides were imaged using a Zeiss Axioskope 2 upright microscope (Branton et al., 2013).

Neuronal counts. $\mathrm{FIV}^{-}$and $\mathrm{FIV}^{+}$coronal left hemibrain sections from A6.5 (including the suprasylvian gyrus, caudate, and hippocampus; Snider and Niemer, 1961) were deparaffinized and stained with cresyl violet $(0.1 \%)$ solution. Slides were then dehydrated and mounted with Acrytol (Leica Microsystems). Neurons with visible nucleoli were counted in cortex (suprasylvian gyrus) and striatum (caudate; $20 \times$ ) and in hippocampus $(\mathrm{CA} 1 ; 40 \times)$ in three nonadjacent fields for each animal, summed, and expressed as the total number of nucleolated neurons per square millimeter. The number of cells in each anatomic site was averaged within groups, as described previously (Maingat et al., 2009).

Statistical analyses. One-way ANOVA with Tukey's multiple-comparison test was used for in vitro experiments with microglia and neurons. Some animal experiments involved two-way comparisons between wild-type and experimental conditions; therefore, twotailed, unpaired $t$ tests for unequal variance were used. Student's $t$ test was used to analyze transcript levels in HIV-infected patients. Statistical tests were applied using Prism version 5 software for OS X (GraphPad). Results are expressed as mean \pm SEM. $p<0.05$ was considered significant.

\section{Results}

IR and neuroimmune gene expression in the brain during HIV-1 infection

HIV-1 infection of the brain is associated with increased expression of proinflammatory genes, chiefly in microglia/macrophages and astrocytes, in response to viral protein expression
(Brackin et al., 1995). Proinflammatory cytokines and chemokines are pivotal contributors to the neuropathogenesis of HIV-1 infection (Katsikis et al., 2011). To examine the extent of immune gene activation in conjunction with IR expression in brain during HIV/AIDS, we analyzed the transcript expression of HLA-DQ1, IL-6, and CXCL10 together with IR, IGF-1R, and PPAR- $\gamma$ gene expression in frontal white matter from HIV/AIDS patients $\left(\mathrm{HIV}^{+}\right)$and other disease controls $\left(\mathrm{HIV}^{-}\right)$. There was significantly increased expression of HLA-DQA1 (Fig. 1A), IL-6 (Fig. $1 B$ ), and CXCL10 (Fig. 1C) in the brains of the $\mathrm{HIV}^{+}$group compared with the $\mathrm{HIV}^{-}$group. PPAR- $\gamma$ showed a trend toward decreased expression in $\mathrm{HIV}^{+}$group (Fig. 1D). The transcript expression of IR (Fig. 1E) and IGF-1R (Fig. $1 F$ ) was similar for the $\mathrm{HIV}^{+}$and $\mathrm{HIV}^{-}$groups.

To verify protein expression of these genes in the brain, immunohistochemistry was performed, revealing minimal $\mathrm{MHC}$ class II immunopositive cells in frontal lobe sections from the $\mathrm{HIV}^{-}$group (Fig. 1G1), whereas there was a marked abundance in macrophage-like cells with MHC class II immunoreactivity in the $\mathrm{HIV}^{+}$group that was apparent in both perivascular and parenchymal regions (Fig. 1G2). Interestingly, PPAR- $\gamma$ immunoreactivity was less evident in the $\mathrm{HIV}^{+}$brain sections (Fig. 1H2) compared with $\mathrm{HIV}^{-}$sections (Fig. 1H1), in which increased PPAR- $\gamma$ immunoreactivity was observed in both nuclei and cytoplasm. Consistent with the gene expression profile, IL-6 immunoreactivity was higher in the $\mathrm{HIV}^{+}$group (Fig. 1I2), whereas IR $\beta$ immunoreactivity was comparable between groups (Fig. $1 J 1, J 2$ ). IR $\beta$ immunostaining was evident on both neurons (arrows) and glia (arrowheads). Therefore, several immune proteins were upregulated, but the IR was unaffected in the brain during HIV/AIDS infection. 

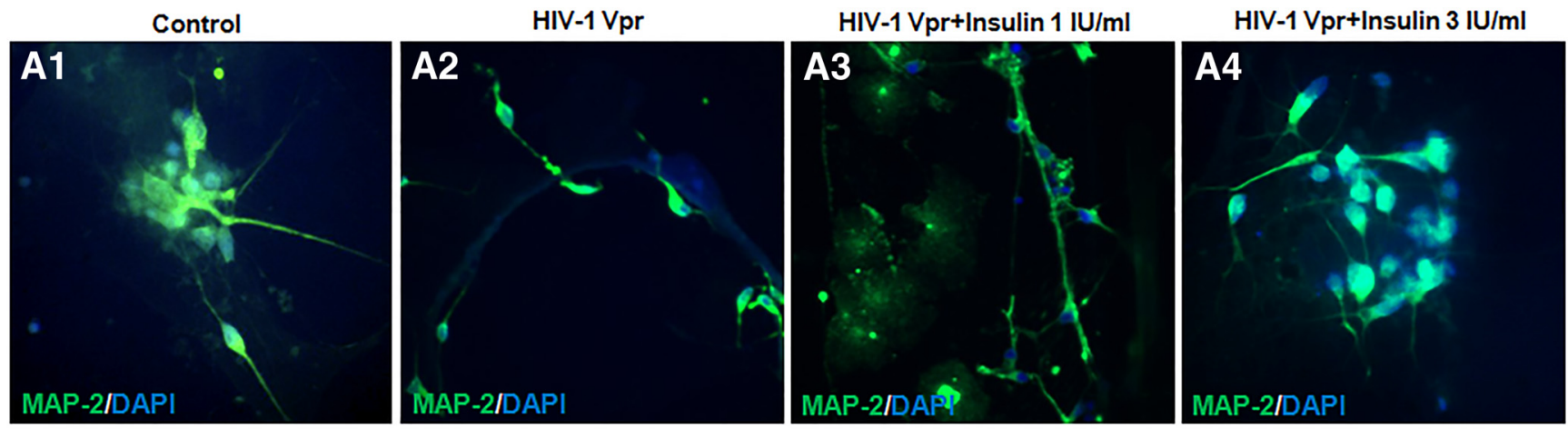

B
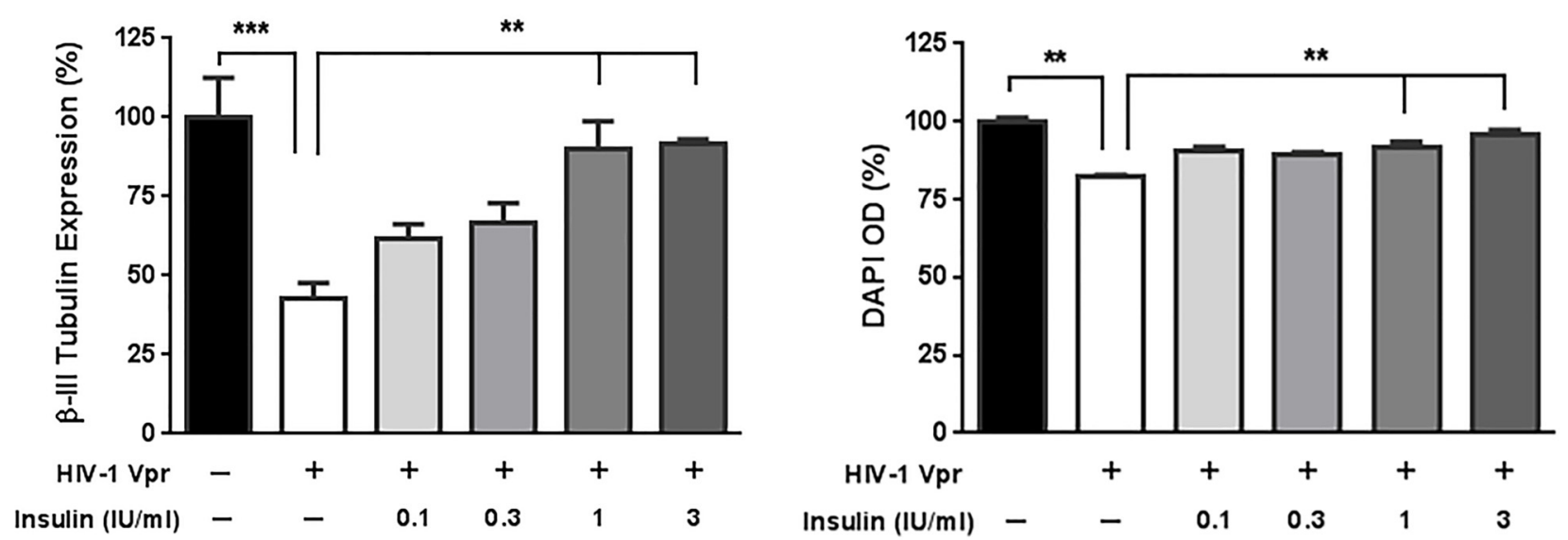

Figure 4. Insulin protects primary human neurons against Vpr-induced neurotoxicity. Primary human neurons were exposed to HIV-1 Vpr (100 nm), followed by treatment with insulin. $A$, MAP-2 immunolabeling (green) merged with DAPI nuclear staining (blue) of healthy neurons (A1) showed a loss of neuronal processes and nuclei with Vpr exposure (A2) that were rescued by insulin treatment at $1.0 \mathrm{IU} / \mathrm{ml}(\boldsymbol{A} 3)$ and $3.0 \mathrm{IU} / \mathrm{ml}(\boldsymbol{A} 4)$. $\boldsymbol{B}$, Class III $\beta$-tubulin ( $\beta$ III-tubulin) expression measured by in-cell Western assay was diminished in Vpr-exposed neurons, but preserved by insulin treatment in a concentration-dependent manner. C, Similarly, neuronal nuclear DAPI staining measured by florescent quantitative analysis at $48 \mathrm{~h}$ after treatment also showed a loss of nuclei with Vpr exposure that was prevent by insulin treatment. Values were normalized to background signals and are expressed as the percentage increase relative to control cells. Data represent mean \pm SEM with a minimum of six replicates per group (one-way ANOVA, post hoc Tukey's test, ${ }^{* * *} p<0.01$ ). Original magnification, $200 \times$.

Insulin inhibits HIV-1 replication in different cell types Previous reports indicated that insulin treatment inhibited HIV-1 replication in different human mononuclear cell lines (Germinario et al., 1995), prompting investigation of the effects of insulin on HIV-1 replication in primary human cells. Insulin treatment of HIV-infected PBMCs resulted in a concentrationdependent reduction in HIV-1 p24 levels in supernatants at day 4 after infection, measured by ELISA. As a positive treatment control, HIV-infected PBMCs were treated with the prototypic reverse transcriptase inhibitor, zidovudine (AZT) which also caused a reduction in HIV-1 p24 levels (Fig. 2A). Insulin treatment of HIV-infected primary human microglia revealed significant reductions in supernatant p24 levels at $5 \mathrm{~d}$ after infection (Fig. 2B). Transduction of human microglia with an HIV-1 clone that was pseudotyped with the VSV-envelope revealed that insulin treatment $(1.0 \mathrm{IU} / \mathrm{ml})$ initiated at the time of transduction suppressed the release of p24 in supernatants at $24 \mathrm{~h}$ after transduction (Fig. 2C). Because insulin inhibited HIV-1 replication, we also examined its actions during FIV infection of a lymphoid cell line (MYA-1), disclosing that insulin reduced FIV replication as measured by reverse transcriptase activity in cell supernatants at day 4 after infection (Fig. 2D). These results confirmed the inhibitory effects of insulin on HIV-1 (and FIV) replication, not only in lymphocytic cells, but also in primary human microglia.
Immune and viral gene expression during insulin treatment of HIV-infected microglia

Neuroinflammation is a key feature of HIV-1 infection of the brain, with microglia being among the chief HIV-permissive and HIVresponsive cells (Garden, 2002). To examine the interactions between insulin treatment and HIV-induced host immune responses in microglia exvivo, we treated HIV-infected primary human microglia with insulin $(1.0 \mathrm{IU} / \mathrm{ml})$ for $5 \mathrm{~d}$, followed by analyses of viral and host gene transcription levels. To extend the studies described above, we examined the expression of HIV-1 pol (Fig. 3A) and $v p r$ (Fig. 3B), which showed that both genes' encoding RNA was detected in HIVinfected microglia, but insulin treatment significantly suppressed viral gene expression, in keeping with above observations (Fig. 2). Although IL-6 expression was not induced in HIV-infected microglia, insulin treatment significantly suppressed $I L-6$ levels in HIVinfected microglia (Fig. 3C). In contrast, CXCL10 mRNA was significantly upregulated in microglia by HIV-1 infection, but was diminished by insulin treatment (Fig. 3D). IL-1 $\beta$ mRNA was upregulated in HIV-infected human microglia, but insulin treatment did not affect IL- $1 \beta$ expression (Fig. 3E). PPAR- $\gamma$ mRNA expression was significantly suppressed in HIV-infected microglia, but was restored by insulin treatment (Fig. $3 F$ ). These findings emphasized insulin's selective anti-inflammatory and antiviral actions on HIVinfected human microglia. 
A

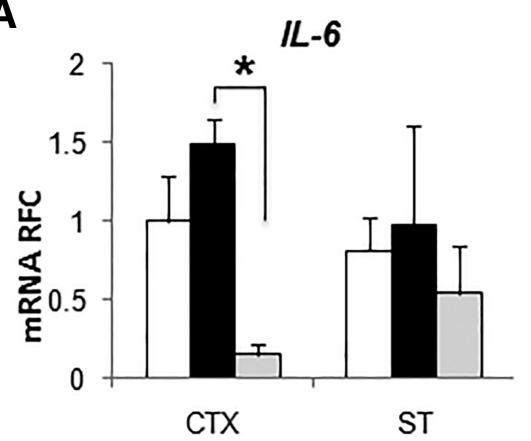

C

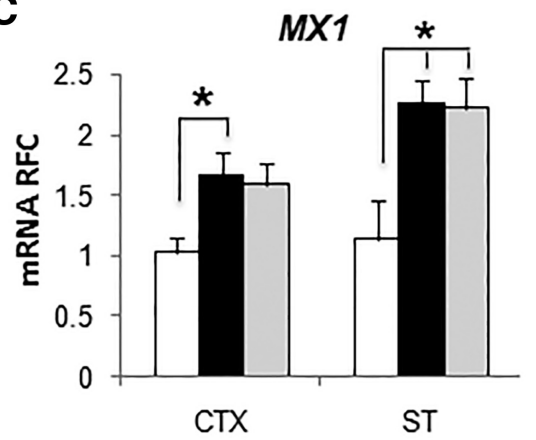

$\mathbf{E}$

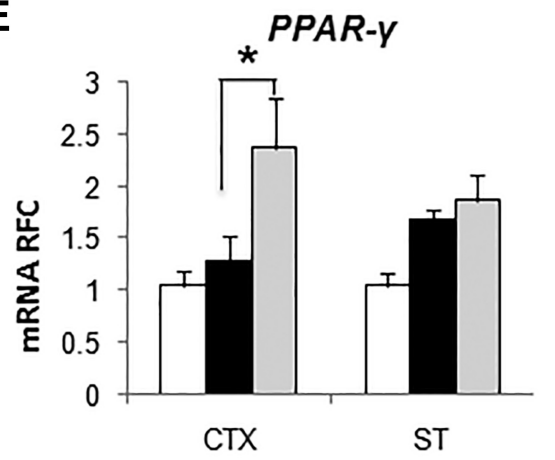

$\mathbf{F}$
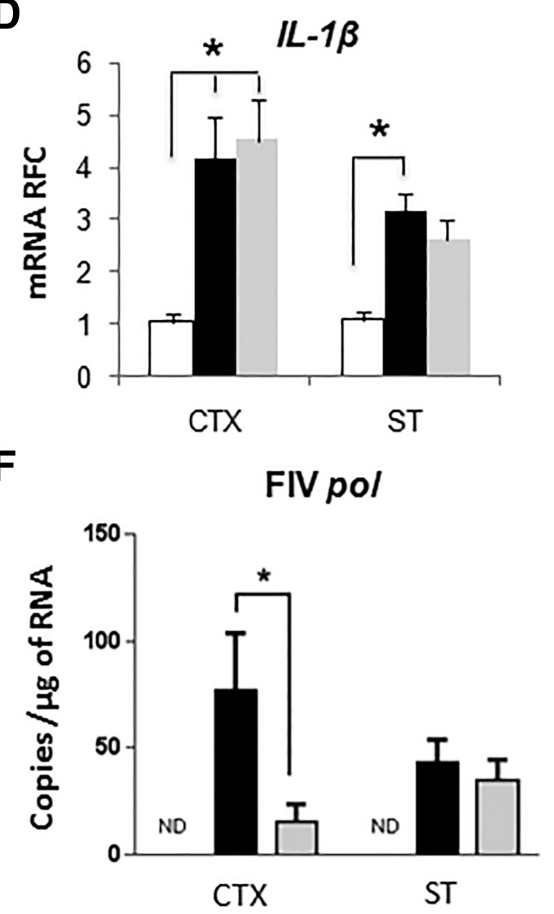

$\square$ FIV[-] (n=5)

$\square$ FIV[+]/PBS ( $n=6)$

$\square$ FIV[+]/insulin ( $=6$ )

Figure 5. Expression of proinflammatory genes in feline cortex (CTX) and striatum (ST). FIV ${ }^{+}$animals were treated with intranasal insulin or PBS for 6 weeks and compared with uninfected FIV ${ }^{-}$animals. Examination of transcript levels showed that IL-6 $(\boldsymbol{A})$ and $C X C L 10(\boldsymbol{B})$ were suppressed in cortex by intranasal insul in treatment in $\mathrm{FIV}^{+}$animals, whereas MX1 (C) and IL-1 $\beta(\boldsymbol{D})$ were induced in both CTX and ST but were unaffected by intranasal insulin treatment. $\boldsymbol{E}$, PPAR- $\gamma$ expression was induced, but FIV pol $(\boldsymbol{F})$ was suppressed in cortex of $\mathrm{FIV}^{+}$animals afater intranasal insulin treatment. Data represent mean \pm SEM (one-way ANOVA, post hoc Tukey's test, ${ }^{*} p<0.05$ ).

Insulin treatment prevents HIV-1 Vpr-mediated neurotoxicity in human neurons

Neuronal injury and the ensuing adverse consequences on neurocognitive performance are important aspects of HIV/AIDS neuropathogenesis (Kaul and Lipton, 2006). The mechanisms underlying neuronal injury are multifold and include the neurotoxic actions of viral proteins. Because the IR was expressed on neurons, human fetal neurons were pretreated for $1 \mathrm{~h}$ with different concentrations of insulin, followed by exposure to the neurotoxic protein HIV-1 Vpr. After HIV-1 Vpr exposure, loss of MAP-2-immunolabeled cell processes was observed (Fig. 4A1,A2), but treatment with insulin reduced $\mathrm{Vpr}$-induced neurotoxicity that was apparent as preserved MAP-2 immunolabeling and increased numbers of DAPI-positive nuclei (Fig. 4A3,A4). Quantitative studies showed that insulin prevented $\mathrm{Vpr}$-induced neurotoxicity, which was evident by increased class III $\beta$-tubulin ( $\beta$ III-tubulin) immunoreactivity in neurons (Fig.
$4 B$ ), with accompanying greater cellular viability, apparent as increased DAPI staining (Fig. $4 \mathrm{C}$ ) at $48 \mathrm{~h}$ after exposure. Therefore, both $\beta$ III-tubulin loss and diminished DAPI detection were rescued by insulin treatment in a concentration-dependent manner, with a maximal effect at $3 \mathrm{IU} / \mathrm{ml}$. MAP-2 is associated with microtubule assembly and microtubules are critical for intracellular transport and cell motility. MAP-2 interacts with $\beta$ III-tubulin, which is critical for neurite extension and vesicular trafficking (Hisaoka et al., 2003). Because both MAP-2 and $\beta$ III-tubulin are markers of neuronal differentiation (Nabiuni et al., 2012), these data suggested that insulin might be acting as a neurotrophic factor affecting neuronal survival and differentiation. These results further underscored insulin's diverse actions in the brain, pointing to specific neuroprotective effects.

In vivo host immune gene expression in the brain during FIV infection

Neuroinflammation typifies lentivirus infections of the nervous system, defined largely by activation of infiltrating leukocytes and glial cells. To explore the effects of in vivo intranasal insulin treatment in a model of HAND, we measured host immune and viral transcript levels in the brains from $\mathrm{FIV}^{+}$vehicle (PBS)- or insulin-treated animals, as well as those from uninfected animals, represented as FIV ${ }^{-}$. IL-6 showed significantly reduced expression in insulintreated $\mathrm{FIV}^{+}$animals in cortex, but its expression in the striatum was similar in both $\mathrm{FIV}^{+}$groups and in $\mathrm{FIV}^{-}$animals (Fig. 5A). Similarly, CXCL10 transcript levels were increased in $\mathrm{FIV}^{+}$animals compared with $\mathrm{FIV}^{-}$animals in both cortex and striatum, whereas insulin treatment reduced CXCL10 in the cortex (Fig. 5B). In contrast, the antiviral gene $M x 1$ (Fig. $5 C$ ) and $I L-1 \beta$ (Fig. 5D) transcript levels were increased in both cortex and striatum of $\mathrm{FIV}^{+}$animals compared with $\mathrm{FIV}^{-}$animals, but were unaffected by insulin treatment. PPAR- $\gamma$ transcript abundance was significantly increased in the cortex, but not striatum, of insulintreated $\mathrm{FIV}^{+}$animals compared with $\mathrm{FIV}^{-}$and PBS-treated $\mathrm{FIV}^{+}$ animal brains (Fig. 5E). FIV pol RNA copy number expression was analyzed by droplet digital PCR and showed viral RNA presence in all $\mathrm{FIV}^{+}$animals; insulin treatment significantly reduced its abundance in cortex, but not in striatum (Fig. $5 F$ ). Notably, IR transcript expression in cortex and striatum was unaffected by FIV infection or insulin treatment (data not shown). These observations emphasized the differential expression of immune markers in the brain after FIV infection, together with the anti-inflammatory and antiviral effects of insulin. Normal blood glucose levels for cats fall between 5.6 and $16.7 \mathrm{mmol} / \mathrm{L}$. Intranasal insulin administration did not affect blood glucose levels, which were $5.3+0.81 \mathrm{mmol} / \mathrm{L}$ (mean $+\mathrm{SD}$ ) before treatment, $6.6+0.79 \mathrm{mmol} / \mathrm{L} 15 \mathrm{~min}$ after treatment, and $7.8+1.63$ $\mathrm{mmol} / \mathrm{L} 90 \mathrm{~min}$ after treatment. 

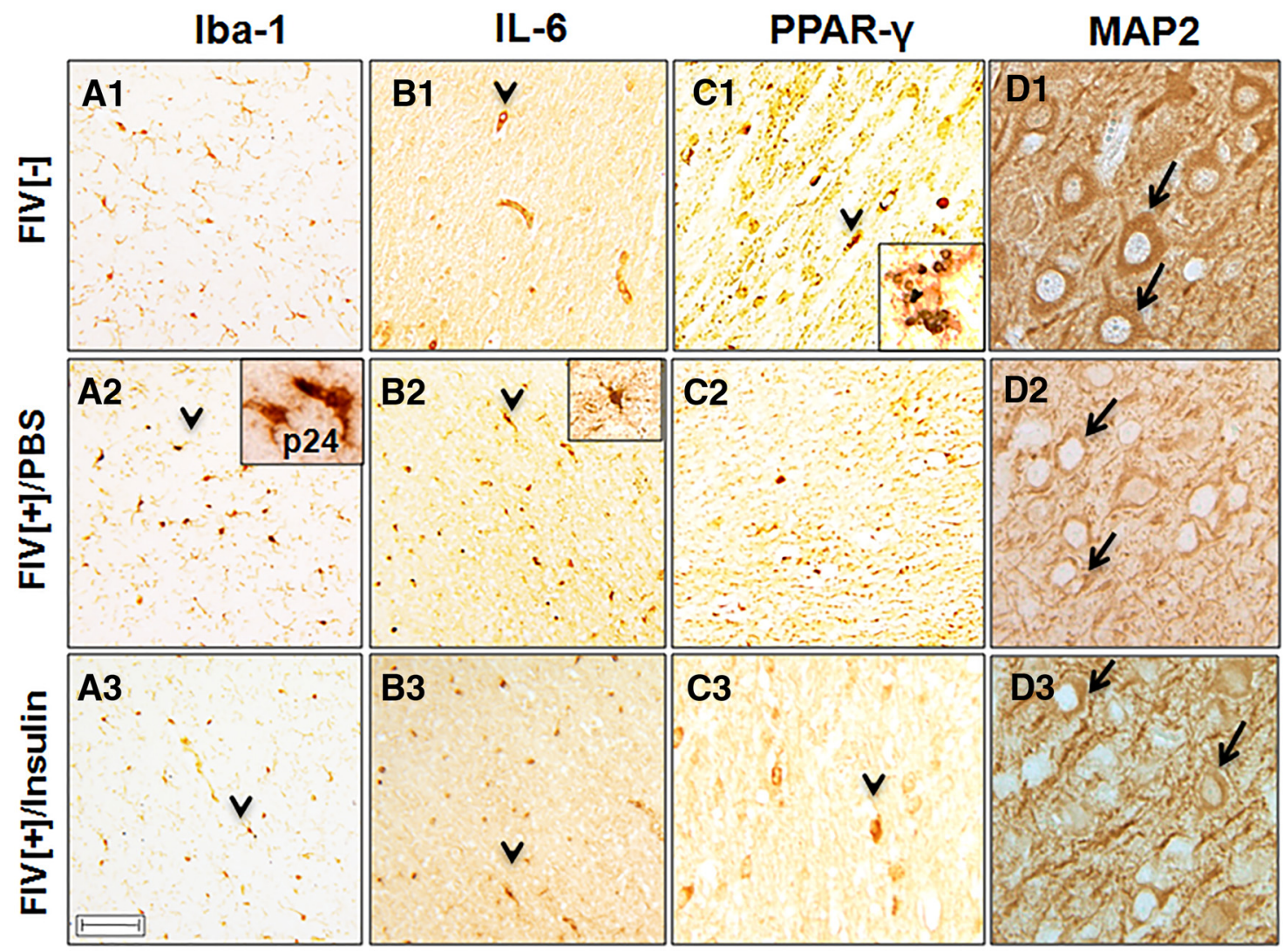

Figure 6. Neuropathological analyses of FIV-infected and uninfected animals. Immunohistochemical studies indicated that, in representative brain sections Iba-1 in cortical microglia $\left(\boldsymbol{A}\right.$, arrowheads) and IL-6 in white matter glia ( $\boldsymbol{B}$, arrowheads) displayed reduced immunoreactivity with insulin treatment of FIV ${ }^{+}$animals. FIV p24 immunoreactvity was detected in cells resembling microglia ( $\boldsymbol{A} \boldsymbol{2}$, inset), whereas IL-6 immunodetection was evident in cells resembling astrocytes ( $\boldsymbol{B} \mathbf{2}$, inset). In contrast, PPAR- $\gamma$ immunoreactivity $(\boldsymbol{C})$ was increased in cortical glia (arrowheads) in both cytoplasm and nuclei ( $\mathbf{C}$, inset) from $\mathrm{FIV}^{+}$animals treated with intranasal insulin. $\boldsymbol{D}$, MAP-2 immunoreactivity was apparent in cortical neuronal cell bodies and processes, but it expression was increased by intranasal insulin treatment of $\mathrm{FIV}^{+}$animals compared with PBS-treated animals. Original magnification: $\boldsymbol{A}-\boldsymbol{C}, 20 \times ; \boldsymbol{D}, 40 \times$. Scale bar, $20 \mu \mathrm{m}$.

\section{Insulin treatment diminishes neuropathology in FIV infection}

To verify the above findings, different immune cell markers were examined in the brains of $\mathrm{FIV}^{+}$and $\mathrm{FIV}^{-}$animals. Iba- 1 immunoreactivity in cortex was present in $\mathrm{FIV}^{-}$animals' brains (Fig. 6A1) and was comparatively increased on cells resembling microglia (arrowhead) in the brains of $\mathrm{FIV}^{+}$animals (Fig. 6A2), which was accompanied by FIV p24 immunoreactivity (inset) compared with $\mathrm{FIV}^{+}$animals receiving insulin treatment (Fig. 6A3). IL-6 immunoreactivity in white matter was minimally detected in $\mathrm{FIV}^{-}$brains except in endothelial cells (Fig. 6B1), but was increased in $\mathrm{FIV}^{+}$animals (Fig. 6B2), specifically in glia (Fig. 6B2, inset), although IL-6 expression in brains was reduced by insulin treatment (Fig. 6B3). PPAR- $\gamma$ immunoreactivity was present in $\mathrm{FIV}^{-}$animals' white matter, chiefly on glial cells (Fig. 6C1, arrowhead), but was reduced during FIV infection (Fig. 6C2), with increased expression after insulin treatment (Fig. 6C3). MAP-2 immunostaining showed numerous neurons in the parietal cortex from $\mathrm{FIV}^{-}$animals (Fig. 6D1). Loss of neuronal processes was evident in the $\mathrm{FIV}^{+}$group's brains (Fig. 6D2), which was reversed in the insulin-treated $\mathrm{FIV}^{+}$group (Fig. 6D3). These findings suggested that intranasal insulin therapy exerted anti-inflammatory effects in white matter and cortex of $\mathrm{FIV}^{+}$animals and confirmed the above ex vivo observations (Figs. 2, 3, 4).

\section{Insulin treatment protects neurons in FIV infection}

Because the above studies suggested that insulin treatment protected neurons during FIV infection, the effects of insulin treatment on different neuronal populations was examined during FIV infection. Nissl staining showed numerous neuronal soma with nucleoli in the cortex from $\mathrm{FIV}^{-}$animals, but the numbers of neurons were reduced in the $\mathrm{FIV}^{+}$brains, together with neuronal preservation in the insulin-treated $\mathrm{FIV}^{+}$group (Fig. $7 \mathrm{~A}$ ). To quantify changes in neurons during FIV infection, analyses of neuronal counts were performed and showed that Nissl-positive neurons with nucleoli were significantly reduced in the brains of $\mathrm{FIV}^{+}$animals compared with the $\mathrm{FIV}^{-}$animals in the parietal cortex (middle suprasylvian gyrus; Fig. $7 B$ ), striatum (caudate; Fig. $7 C$ ), and the CA1 region of the hippocampus (Fig. $7 D$ ). However, neuronal counts were significantly higher in insulin-treated $\mathrm{FIV}^{+}$compared with PBS-treated $\mathrm{FIV}^{+}$animals in each anatomic site, with the greatest neuroprotective effect apparent in the hippocampus. These findings highlighted the protective effects of insulin on different neuronal populations.

\section{Insulin treatment improves neurobehavioral outcomes in FIV infection}

The most evident and perhaps relevant indicator of neurological disease is quantitative neurobehavioral performance. Executive (impaired memory and decision making) and motor abnormal- 
A
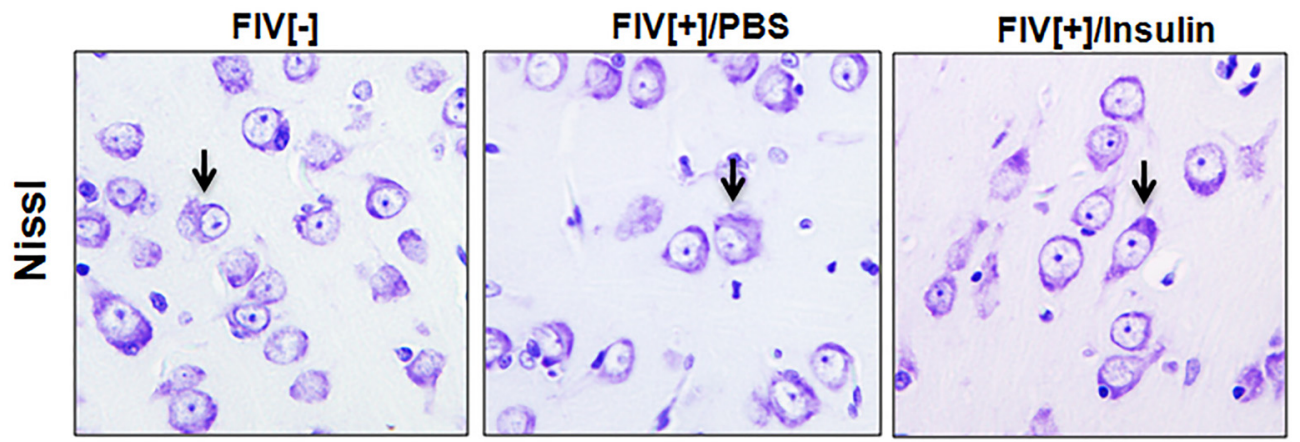

B

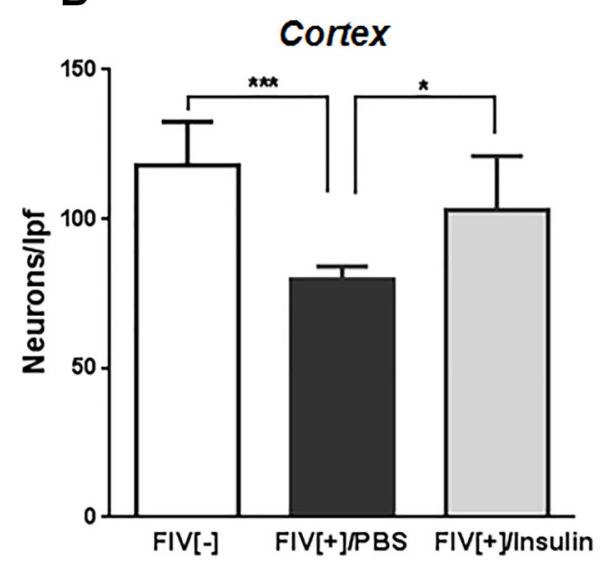

C

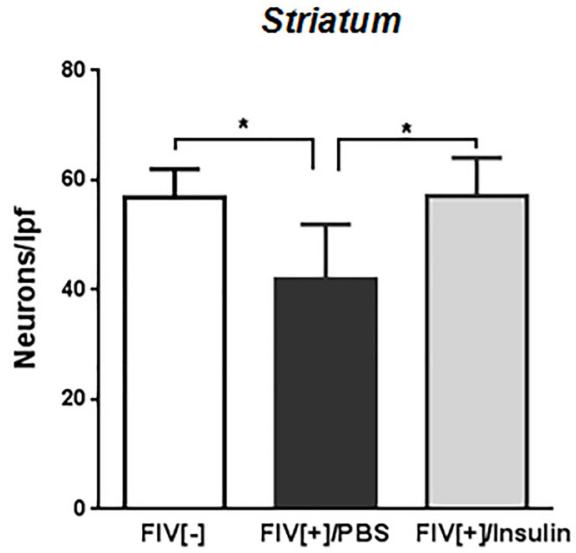

D

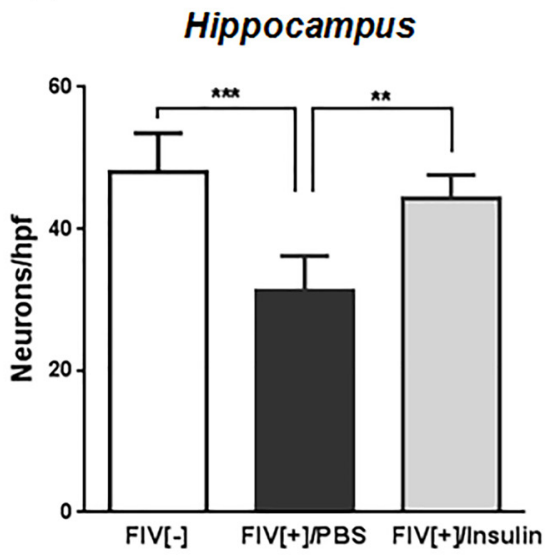

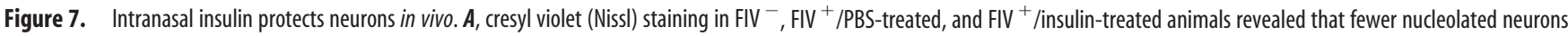
(arrows) in the middle suprasylvian gyrus were detected in FIV ${ }^{+} / \mathrm{PBS}$-treated animals. Neurons with nucleoli were counted in the cortex (suprasylvian gyrus; $\boldsymbol{B}$ ), striatum (caudate; $\boldsymbol{C}$, and CA1 region $(\boldsymbol{D})$ of the hippocampus. Mean neuronal counts $\left(\boldsymbol{B}, \boldsymbol{C}\right.$, cell number $/ 1.0 \mathrm{~mm}{ }^{2}$ low-power field, Ipf, and $\boldsymbol{D}$, cell number $/ 0.25 \mathrm{~mm}{ }^{2}$ high-power field, hpf) were lower in each anatomic site among $\mathrm{PBS}$-treated FIV $^{+}$animals compared with FIV ${ }^{-}$animals, but intranasal insulin treatment prevented neuronal loss in all brain regions. Data represent mean \pm SEM (one-way ANOVA, post hoc Tukey's test, $\left.{ }^{*} p<0.05\right)$.

ities (delayed responses and ataxia) represent frequently encountered clinical signs and symptoms among patients with HAND (Boissé et al., 2008). The in vivo impact of insulin treatment on neurobehavioral performance was assessed in $\mathrm{FIV}^{-}$animals and compared with $\mathrm{FIV}^{+}$animals in the presence or absence of intranasal insulin treatment. Analyses of motor speed measured by maze completion times revealed that $\mathrm{FIV}^{+}$animals were slower than insulin-treated $\mathrm{FIV}^{+}$and $\mathrm{FIV}^{-}$animals (Fig. 8A). $\mathrm{FIV}^{+}$ animals also showed increased variance in gait width, which is indicative of ataxia, compared with $\mathrm{FIV}^{+}$animals receiving insulin therapy and $\mathrm{FIV}^{-}$animals at 12 weeks after infection (Fig. $8 B$ ). To assess spatial memory and decision making in the same groups, the number of errors incurred during completion of the maze task was recorded, disclosing that $\mathrm{FIV}^{+}$animals made more errors than insulin-treated $\mathrm{FIV}^{+}$and $\mathrm{FIV}^{-}$animals (Fig. 8C). Finally, to assess motor memory performance, animals performed an object memory task, in which $\mathrm{FIV}^{+}$animals completed fewer successful steps compared with insulin-treated $\mathrm{FIV}^{+}$and FIV ${ }^{-}$animals (Fig. 8D). Overall, these studies demonstrated that $\mathrm{FIV}^{+}$animals exhibited a greater number of deficits suggestive of more severe neurological disease compared with $\mathrm{FIV}^{-}$animals and that insulin-treated $\mathrm{FIV}^{+}$animals performed significantly better in all neurobehavioral domains relative to PBS-treated $\mathrm{FIV}^{+}$animals.

\section{Discussion}

The present study verifies and extends earlier studies indicating that insulin exerts inhibitory effects on HIV-1 replication and proinflam- matory gene expression and also shows that insulin treatment improved neurological outcomes in multiple HIV-related model systems. In particular, insulin suppressed HIV-1 and FIV replication at physiological concentrations while also reducing the ex vivo and in vivo expression of IL-6 and CXCL10 in parallel with inducing PPAR- $\gamma$ expression, which led to improved in vivo neurological function. These findings underscore the potent actions of insulin in the brain and also provide a rationale for examining its preventative and therapeutic effects in a clinical setting among patients with HAND.

Although the present data suggested that HIV-1 infection did not affect IR expression in the brain, insulin appeared to influence several processes in both glia and neurons. In HIV-infected microglia, insulin treatment induced the expression of PPAR- $\gamma$, which is a downstream consequence of IR signaling (Seto-Young et al., 2007). Interestingly, we did not observe changes in PPAR- $\gamma$ or HIV-1 expression mediated by insulin treatment of THP-1 cells (data not shown). The most likely explanation for the absence of insulin-mediated effects in THP-1 cells is the recognized aberrant insulin signaling cascade, as reported earlier (Uddin et al., 1997). The present results were consistent with previous reports indicating that PPAR- $\gamma$ is an important insulin-regulated gene (for review, see Leonardini et al., 2009). Indeed, these findings point to both direct and indirect PPAR- $\gamma$-mediated regulation of CXCL10, which is similar to previous studies highlighting the inhibitory role of PPAR- $\gamma$ activation on CXCL10 expression in fibroblasts and adipocytes (Antonelli et al., 2006; Ofengeim et 
al., 2012). In combination with this effect, we observed suppression of IL-6 and CXCL10 expression ex vivo and in vivo in response to insulin treatment. (Takeshita et al., 1995; Yao et al., 2010). The explanation for reduced PPAR- $\gamma$ in the brain during HIV/AIDS is unclear, but our group's data derived from microRNA analyses in the brain showed several upregulated microRNAs that potentially target PPAR- $\gamma$ expression (Noorbakhsh et al., 2010). PPAR- $\gamma$ agonists suppressed $\mathrm{HIV}-1$ replication in vitro and in vivo, underscoring the ability of PPAR- $\gamma$ to suppress HIV-1 replication in the brain (Potula et al., 2008). Future studies are imperative to unravel this mechanism in greater detail.

HIV-1 Vpr readily crosses cell membranes and mediates the apoptosis of neurons and other cell types (Muthumani et al., 2002; Jones et al., 2007; Belzile et al., 2007; Patel et al., 2000). In the context of Vpr's proapoptotic effects on neurons, ligation of the glucocorticoid receptor is more likely the mechanism for mediating apoptosis because neurons are terminally differentiated cells. In fact, we showed previously that $\mathrm{Vpr}$ acted through the mitochondrial/caspase-9 death pathway to cause human neuronal apoptosis (Jones et al., 2007) and other groups have implicated Vpr in reduced axonal outgrowth by impairing mitochondrial function (Kitayama et al., 2008). In the present experiments, Vpr might be mediating latter mechanism given the reduced $\beta$ IIItubulin expression in Vpr-exposed neurons (Fig. 4). Insulin could activate the neuronal cytoskeletal-associated protein merlin/NF2, which interacts with VprBP (Kim et al., 2012). Interestingly, the concentration of insulin is critical for neurite outgrowth, as demonstrated in a recent study (Singh et al., 2012). In peripheral sensory neurons, higher concentrations of insulin led to resistance of neurite outgrowth, whereas lower concentrations increased neurite outgrowth. Regardless of the underlying mechanism, insulin (1-3 IU/ml) prevented neuronal process retraction and cell death in the present ex vivo studies using primary human neurons and also protected neurons in vivo in vulnerable anatomic locations (cortex, striatum, and hippocampus; Fig. 7), in keeping with its growth-promoting and prometabolic properties. This supposition is supported by a recent report of a rodent model of HAND in which metabolic changes in brain were improved by intranasal insulin treatment (Kim et al., 2015).

In the present studies, neuroimmune activation in $\mathrm{FIV}^{+}$animals was more evident in the cerebral cortex compared with the striatum. This anatomically specific effect might reflect differential blood (or the recently described lymphatic) circulation to the cortex versus the striatum. Indeed, this anatomic dichotomy was also apparent for the effects of intranasal insulin because it had greater effects on the expression of CXCL10 and IL- 6 in the cortex. Recent reports suggested that intranasal insulin's beneficial actions in dementia patients likely predominated in the cortex because cortical functions (memory and mood) showed the most robust benefits (Claxton et al., 2015). The mechanisms by which
B

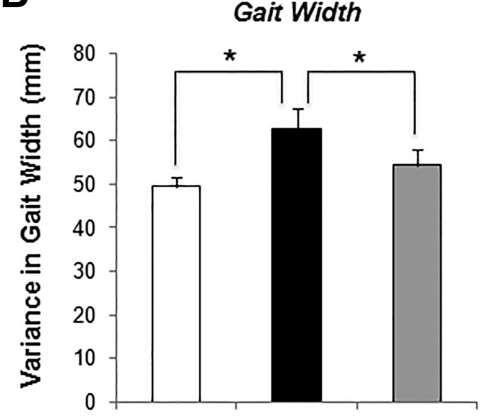

D

Object Memory Task

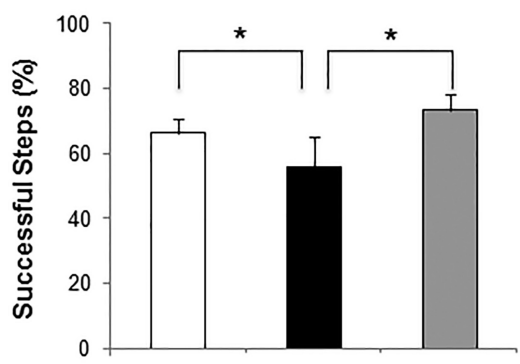

\section{FIVI-] (n=5) $\square[+] / P B S(n=6) \quad \square$ FIV[+]/insulin (n=6)}
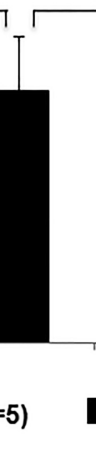

animals. Analyses of neurobehavioral functions in FIV $(n=5)$, FIV ${ }^{+} / \mathrm{PBS}^{-t r e a t e d}(n=6)$, and FIV ${ }^{+} /$insulin-treated $(n=6)$ animals showing improved neurobehavioral performance with insulin treatment, as assessed by maze completion time $(\boldsymbol{A})$ and gait variance $(\boldsymbol{B})$. Insulin treatment improved decision making and motor memory in $\mathrm{FIV}^{+}$animals, as assessed by maze errors $(\boldsymbol{C})$ and object memory task $(\boldsymbol{D})$. Data represent mean \pm Tukey'stest, $\left.{ }^{*} p<0.05\right)$

intranasal insulin accesses the brain and enables improved neurological outcomes are uncertain. Studies of rodents suggest that intranasal insulin delivery provides uniform drug distribution through the brain, which might reflect differential cerebral blood or lymphatic circulation in rodents versus higher species (for review, see Gray et al., 2014). In the current studies, the changes in host (and viral) gene expression with insulin treatment were chiefly observed in the cortex, although insulin's neuroprotective actions were evident in all brain regions (cortex, caudate, and hippocampus). The reduced antiviral and anti-inflammatory effects of insulin in subcortical regions could be problematic in clinical studies in which the neurological disorder is characterized by substantial subcortical pathology (e.g., HAND, Parkinson's disease). Insulin-mediated neuronal preservation was evident in the striatum and hippocampus, implying that the antiinflammatory and antiviral effects of intranasal insulin might be less potent than its neuroprotective actions. This observation is reinforced by the substantial therapeutic effect of insulin on the maze task, which is principally a hippocampal function (Fig. 8). This issue will require further analyses when establishing a clinical trial of intranasal insulin in HAND because it is widely assumed that HIV-1 is concentrated in the striatum and associated white matter (Kure et al., 1990). A related issue is the effect of insulin on other cell types including astrocytes and oligodendrocytes. Both insulin and IGF-1 exert trophic effects on these cell types and, in principle, insulin would be beneficial to the growth and survival of these cells. Nonetheless, the issue of hypoglycemia and potentially low glucose levels in brain are of concern here. Based on our pilot studies, hypoglycemia was not encountered at 
the present in vivo dose, which is similar to clinical trials in Alzheimer's disease(for review, see Shemesh et al., 2012). Several studies have demonstrated that blood glucose and insulin levels remain unchanged after intranasal insulin administration (Benedict et al., 2004; Kulstad et al., 2006). It is possible that intranasal insulin treatment is also active at the IGF-1 receptors, potentially amplifying growth or metabolic effects or possibly blocking HIV-1 gp120 binding to IGF-1R2, a putative receptor for HIV-1 (Dohgu et al., 2012). The concentrations of insulin used herein reflect physiological insulin levels in CSF of human $(\sim 1.0 \mathrm{IU} / \mathrm{ml})$ and the dosage used in human clinical trials (Reger et al., 2008). Our studies of insulin treatment of VSV-pseudotyped infection of microglia suggested that insulin could act by blocking HIV-1 infection and repressing HIV-1 replication, as reported by earlier studies of insulin treatment of HIV-infected leukocytes (Germinario et al., 1995).

Several issues remain unclear in the present study. The duration and trajectory of insulin's beneficial actions on neurobehavioral performance are uncertain because the animals were treated for only 6 weeks. Studies in HAND patients will be required to address this question because there might be temporal limits to insulin's benefits on neurocognitive performance. The dose of insulin used in the present studies was limited by the risk of hypoglycemia; however, the maximal dose will likely also be dictated by the general health of the treated subject, with older individuals being less tolerant of higher doses of intranasal insulin. The present in vivo model best recapitulates HAND in children because we used adolescent animals, so the present effects of intranasal insulin might be more (or less) apparent in older animals (and humans). Insulin resistance in the periphery and perhaps within the brain might be associated with neurocognitive decline; however, the mechanisms of insulin resistance in the brain are not understood (Benedict et al., 2012). Peripheral insulin resistance might not reflect CNS insulin resistance (Banks et al., 2012). Chronic insulin treatment could lead to desensitization of IRs, but randomized controlled clinical trials of intranasal insulin treatment in Alzheimer's disease have shown beneficial effects despite putatively impaired insulin signaling in the CNS during the disease (Freiherr et al., 2013; Kim and Feldman, 2015). Therefore, studies of longer duration are required to address whether insulin resistance could be a possible challenge. Finally, the underlying mechanism by which insulin mediates its favorable effects requires further investigation. PPAR- $\gamma$ activation appears to be associated with reduced inflammatory gene expression, but the precise signaling pathway remains to be determined fully.

Although the present results point to insulin as an effective suppressor of lentivirus replication and associated neuroinflammation, the definitive analysis will be a test of its effects in patients with HAND. To our knowledge, at least two clinical trials of intranasal insulin in HAND are in the planning stages now and will be opened within the next year. In the meantime, further studies in other animal models are warranted to validate the dosage schedule and glean insights into the mechanism(s) by which insulin facilitates improvement in neurological outcomes.

\section{References}

Antonelli A, Rotondi M, Ferrari SM, Fallahi P, Romagnani P, Franceschini SS, Serio M, Ferrannini E (2006) Interferon-gamma-inducible alphachemokine CXCL10 involvement in Graves' ophthalmopathy: modulation by peroxisome proliferator-activated receptor-gamma agonists. J Clin Endocrinol Metab 91:614-620. CrossRef Medline

Banks WA, Owen JB, Erickson MA (2012) Insulin in the brain: there and back again. Pharmacol Ther 136:82-93. CrossRef Medline
Barbagallo M, Dominguez LJ (2014) Type 2 diabetes mellitus and Alzheimer's disease. World J Diabetes 5:889-893. CrossRef Medline

Belzile JP, Duisit G, Rougeau N, Mercier J, Finzi A, Cohen EA (2007) HIV-1 Vpr-mediated G2 arrest involves the DDB1-CUL4AVPRBP E3 ubiquitin ligase. PLoS Pathog 3:e85. CrossRef Medline

Benedict C, Hallschmid M, Hatke A, Schultes B, Fehm HL, Born J, Kern W (2004) Intranasal insulin improves memory in humans. Psychoneuroendocrinology 29:1326-1334. CrossRef Medline

Benedict C, Brooks SJ, Kullberg J, Burgos J, Kempton MJ, Nordenskjöld R, Nylander R, Kilander L, Craft S, Larsson EM, Johansson L, Ahlström H, Lind L, Schiöth HB (2012) Impaired insulin sensitivity as indexed by the HOMA score is associated with deficits in verbal fluency and temporal lobe gray matter volume in the elderly. Diabetes Care 35:488-494. CrossRef Medline

Boissé L, Gill MJ, Power C (2008) HIV infection of the central nervous system: clinical features and neuropathogenesis. Neurol Clin 26:799_ 819, x. CrossRef Medline

Brackin MN, Lewis RE, Brackin BT, Achord A, Henderson H, Crawford M, Cruse JM (1995) Progression of HIV infection is associated with HLA-DQ antigens in Caucasians and African Americans. Pathobiology 63:22-41. CrossRef Medline

Branton WG, Ellestad KK, Maingat F, Wheatley BM, Rud E, Warren RL, Holt RA, Surette MG, Power C (2013) Brain microbial populations in HIV/ AIDS: alpha-proteobacteria predominate independent of host immune status. PLoS One 8:e54673. CrossRef Medline

Brown WC, Bissey L, Logan KS, Pedersen NC, Elder JH, Collisson EW (1991) Feline immunodeficiency virus infects both $\mathrm{CD} 4+$ and CD8 + T lymphocytes. J Virol 65:3359-3364. Medline

Brunner D, Pedersen NC (1989) Infection of peritoneal macrophages in vitro and in vivo with feline immunodeficiency virus. J Virol 63:54835488. Medline

Claxton A, Baker LD, Hanson A, Trittschuh EH, Cholerton B, Morgan A, Callaghan M, Arbuckle M, Behl C, Craft S (2015) Long-acting intranasal insulin detemir improves cognition for adults with mild cognitive impairment or early-stage Alzheimer's disease dementia. J Alzheimers Dis 44: 897-906. CrossRef Medline

Clements JE, Zink MC, Narayan O, Gabuzda DH (1994) Lentivirus infection of macrophages. Immunol Ser 60:589-600. Medline

Derakhshan F, Toth C (2013) Insulin and the brain. Curr Diabetes Rev 9:102-116. Medline

Dohgu S, Ryerse JS, Robinson SM, Banks WA (2012) Human immunodeficiency virus-1 uses the mannose-6-phosphate receptor to cross the blood-brain barrier. PLoS One 7:e39565. CrossRef Medline

Fletcher NF, Brayden DJ, Brankin B, Callanan JJ (2008) Feline immunodeficiency virus infection: a valuable model to study HIV-1 associated encephalitis. Vet Immunol Immunopathol 123:134-137. CrossRef Medline

Freiherr J, Hallschmid M, Frey WH 2nd, Brünner YF, Chapman CD, Holscher C, Craft S, De Felice FG, Benedict C (2013) Intranasal insulin as a treatment for Alzheimer's disease: a review of basic research and clinical evidence. CNS Drugs 27:505-514. CrossRef Medline

Gannon P, Khan MZ, Kolson DL (2011) Current understanding of HIVassociated neurocognitive disorders pathogenesis. Curr Opin Neurol 24: 275-283. CrossRef Medline

Garden GA (2002) Microglia in human immunodeficiency virus-associated neurodegeneration. Glia 40:240-251. CrossRef Medline

Gerena Y, Skolasky RL, Velez JM, Toro-Nieves D, Mayo R, Nath A, Wojna V (2012) Soluble and cell-associated insulin receptor dysfunction correlates with severity of HAND in HIV-infected women. PLoS One 7:e37358. CrossRef Medline

Germinario RJ, DeSantis T, Wainberg MA (1995) Insulin-like growth factor 1 and insulin inhibit HIV type 1 replication in cultured cells. AIDS Res Hum Retroviruses 11:555-561. CrossRef Medline

Gonzalez-Scarano F, Martín-García J (2005) The neuropathogenesis of AIDS. Nat Rev Immunol 5:69-81. CrossRef Medline

Gray SM, Meijer RI, Barrett EJ (2014) Insulin regulates brain function, but how does it get there? Diabetes 63:3992-3997. CrossRef Medline

Heaton RK et al. (2011) HIV-associated neurocognitive disorders before and during the era of combination antiretroviral therapy: differences in rates, nature, and predictors. J Neurovirol 17:3-16. CrossRef Medline

Hisaoka M, Okamoto S, Koyama S, Ishida T, Imamura T, Kanda H, Kameya T, Meis-Kindblom JM, Kindblom LG, Hashimoto H (2003) Microtubule-associated protein-2 and class III beta-tubulin are expressed 
in extraskeletal myxoid chondrosarcoma. Mod Pathol 16:453-459. CrossRef Medline

Johnston J, Power C (1999) Productive infection of human peripheral blood mononuclear cells by feline immunodeficiency virus: implications for vector development. J Virol 73:2491-2498. Medline

Johnston JB, Silva C, Hiebert T, Buist R, Dawood MR, Peeling J, Power C (2002) Neurovirulence depends on virus input titer in brain in feline immunodeficiency virus infection: evidence for activation of innate immunity and neuronal injury. J Neurovirol 8:420-431. CrossRef Medline

Jones GJ, Barsby NL, Cohen EA, Holden J, Harris K, Dickie P, Jhamandas J, Power C (2007) HIV-1 Vpr causes neuronal apoptosis and in vivo neurodegeneration. J Neurosci 27:3703-3711. CrossRef Medline

Katsikis PD, Mueller YM, Villinger F (2011) The cytokine network of acute HIV infection: a promising target for vaccines and therapy to reduce viral set-point? PLoS Pathog 7:e1002055. CrossRef Medline

Kaul M, Lipton SA (2006) Mechanisms of neuroimmunity and neurodegeneration associated with HIV-1 infection and AIDS. J Neuroimmune Pharmacol 1:138-151. CrossRef Medline

Kim B, Feldman EL (2015) Insulin resistance as a key link for the increased risk of cognitive impairment in the metabolic syndrome. Exp Mol Med 47:e149. CrossRef Medline

Kim B-H, Alt J, Rojas C, Hadas E, Kelschenbach J, Borjabad A, Thomas AG, Volsky DJ, Slusher BS (2015) Treatment of EcoHIV-infected mice with intranasal insulin abrogates cognitive impairment and normalizes energy metabolic alterations associated with HAND. J Neurovirol 21:36.

Kim K, Heo K, Choi J, Jackson S, Kim H, Xiong Y, An W (2012) Vprbinding protein antagonizes p53-mediated transcription via direct interaction with $\mathrm{H} 3$ tail. Mol Cell Biol 32:783-796. CrossRef Medline

Kitayama H, Miura Y, Ando Y, Hoshino S, Ishizaka Y, Koyanagi Y (2008) Human immunodeficiency virus type $1 \mathrm{Vpr}$ inhibits axonal outgrowth through induction of mitochondrial dysfunction. J Virol 82:2528-2542. CrossRef Medline

Kolenda-Roberts HM, Kuhnt LA, Jennings RN, Mergia A, Gengozian N, Johnson CM (2007) Immunopathogenesis of feline immunodeficiency virus infection in the fetal and neonatal cat. Front Biosci 12:3668-3682. CrossRef Medline

Kulstad JJ, Green PS, Cook DG, Watson GS, Reger MA, Baker LD, Plymate SR, Asthana S, Rhoads K, Mehta PD, Craft S (2006) Differential modulation of plasma beta-amyloid by insulin in patients with Alzheimer disease. Neurology 66:1506-1510. CrossRef Medline

Kure K, Weidenheim KM, Lyman WD, Dickson DW (1990) Morphology and distribution of HIV-1 gp41-positive microglia in subacute AIDS encephalitis: pattern of involvement resembling a multisystem degeneration. Acta Neuropathol 80:393-400. CrossRef Medline

Leonardini A, Laviola L, Perrini S, Natalicchio A, Giorgino F (2009) Crosstalk between PPARgamma and insulin signaling and modulation of insulin sensitivity. PPAR Res 2009:818945. CrossRef Medline

Maingat F, Vivithanaporn P, Zhu Y, Taylor A, Baker G, Pearson K, Power C (2009) Neurobehavioral performance in feline immunodeficiency virus infection: integrated analysis of viral burden, neuroinflammation, and neuronal injury in cortex. J Neurosci 29:8429-8437. CrossRef Medline

McArthur JC, Steiner J, Sacktor N, Nath A (2010) Human immunodeficiency virus-associated neurocognitive disorders: mind the gap. Ann Neurol 67:699-714. CrossRef Medline

Meeker RB, Asahchop E, Power C (2014) The brain and HAART: collaborative and combative connections. Curr Opin HIV AIDS 9:579-584. CrossRef Medline

Muthumani K, Hwang DS, Desai BM, Zhang D, Dayes N, Green DR, Weiner DB (2002) HIV-1 Vprinduces apoptosis through caspase 9 in T cells and peripheral blood mononuclear cells. J Biol Chem 277:37820-37831. CrossRef Medline

Na H, Acharjee S, Jones G, Vivithanaporn P, Noorbakhsh F, McFarlane N, Maingat F, Ballanyi K, Pardo CA, Cohen EA, Power C (2011) Interactions between human immunodeficiency virus (HIV)-1 Vpr expression and innate immunity influence neurovirulence. Retrovirology 8:44. CrossRef Medline

Nabiuni M, Rasouli J, Parivar K, Kochesfehani HM, Irian S, Miyan JA (2012) In vitro effects of fetal rat cerebrospinal fluid on viability and neuronal differentiation of PC12 cells. Fluids Barriers CNS 9:8. CrossRef Medline

Nakagawa F, Miners A, Smith CJ, Simmons R, Lodwick RK, Cambiano V, Lundgren JD, Delpech V, Phillips AN (2015) Projected lifetime health- care costs associated with HIV infection. PLoS One 10:e0125018. CrossRef Medline

Nightingale S, Winston A, Letendre S, Michael BD, McArthur JC, Khoo S, Solomon T (2014) Controversies in HIV-associated neurocognitive disorders. Lancet Neurol 13:1139-1151. CrossRef Medline

Noorbakhsh F, Ramachandran R, Barsby N, Ellestad KK, LeBlanc A, Dickie P, Baker G, Hollenberg MD, Cohen EA, Power C (2010) MicroRNA profiling reveals new aspects of HIV neurodegeneration: caspase- 6 regulates astrocyte survival. FASEB J 24:1799-1812. CrossRef Medline

Ofengeim D, Shi P, Miao B, Fan J, Xia X, Fan Y, Lipinski MM, Hashimoto T, Polydoro M, Yuan J, Wong ST, Degterev A (2012) Identification of small molecule inhibitors of neurite loss induced by Abeta peptide using high content screening. J Biol Chem 287:8714-8723. CrossRef Medline

Olmsted RA, Hirsch VM, Purcell RH, Johnson PR (1989) Nucleotide sequence analysis of feline immunodeficiency virus: genome organization and relationship to other lentiviruses. Proc Natl Acad Sci U S A 86:80888092. CrossRef Medline

Patel CA, Mukhtar M, Pomerantz RJ (2000) Human immunodeficiency virus type $1 \mathrm{Vpr}$ induces apoptosis in human neuronal cells. J Virol 74: 9717-9726. CrossRef Medline

Polyak MJ, Vivithanaporn P, Maingat FG, Walsh JG, Branton W, Cohen EA, Meeker R, Power C (2013) Differential type 1 interferon-regulated gene expression in the brain during AIDS: interactions with viral diversity and neurovirulence. FASEB J 27:2829-2844. CrossRef Medline

Potula R, Ramirez SH, Knipe B, Leibhart J, Schall K, Heilman D, Morsey B, Mercer A, Papugani A, Dou H, Persidsky Y (2008) Peroxisome proliferator-activated receptor-gamma activation suppresses HIV-1 replication in an animal model of encephalitis. AIDS 22:1539-1549. CrossRef Medline

Power C, Johnson RT (2001) Neuroimmune and neurovirological aspects of human immunodeficiency virus infection. Adv Virus Res 56:389-433. CrossRef Medline

Power C, Buist R, Johnston JB, Del Bigio MR, Ni W, Dawood MR, Peeling J (1998a) Neurovirulence in feline immunodeficiency virus-infected neonatal cats is viral strain specific and dependent on systemic immune suppression. J Virol 72:9109-9115. Medline

Power C, McArthur JC, Nath A, Wehrly K, Mayne M, Nishio J, Langelier T, Johnson RT, Chesebro B (1998b) Neuronal death induced by brainderived human immunodeficiency virus type 1 envelope genes differs between demented and nondemented AIDS patients. J Virol 72:90459053. Medline

Reger MA, Watson GS, Green PS, Baker LD, Cholerton B, Fishel MA, Plymate SR, Cherrier MM, Schellenberg GD, Frey WH 2nd, Craft S (2008) Intranasal insulin administration dose-dependently modulates verbal memory and plasma amyloid-beta in memory-impaired older adults. J Alzheimers Dis 13:323-331. Medline

Schnell G, Joseph S, Spudich S, Price RW, Swanstrom R (2011) HIV-1 replication in the central nervous system occurs in two distinct cell types. PLoS Pathog 7:e1002286. CrossRef Medline

Seto-Young D, Avtanski D, Strizhevsky M, Parikh G, Patel P, Kaplun J, Holcomb K, Rosenwaks Z, Poretsky L (2007) Interactions among peroxisome proliferator activated receptor-gamma, insulin signaling pathways, and steroidogenic acute regulatory protein in human ovarian cells. J Clin Endocrinol Metab 92:2232-2239. CrossRef Medline

Shemesh E, Rudich A, Harman-Boehm I, Cukierman-Yaffe T (2012) Effect of intranasal insulin on cognitive function: a systematic review. J Clin Endocrinol Metab 97:366-376. CrossRef Medline

Shen A, Yang HC, Zhou Y, Chase AJ, Boyer JD, Zhang H, Margolick JB, Zink MC, Clements JE, Siliciano RF (2007) Novel pathway for induction of latent virus from resting CD4(+) T cells in the simian immunodeficiency virus/macaque model of human immunodeficiency virus type 1 latency. J Virol 81:1660-1670. CrossRef Medline

Silva C, Zhang K, Tsutsui S, Holden JK, Gill MJ, Power C (2003) Growth hormone prevents human immunodeficiency virus-induced neuronal p53 expression. Ann Neurol 54:605-614. CrossRef Medline

Singh B, Xu Y, McLaughlin T, Singh V, Martinez JA, Krishnan A, Zochodne DW (2012) Resistance to trophic neurite outgrowth of sensory neurons exposed to insulin. J Neurochem 121:263-276. CrossRef Medline

Snider RS, Niemer WT (1961) A stereotaxic atlas of the cat brain. Chicago: University of Chicago. 
Suh HS, Lo Y, Choi N, Letendre S, Lee SC (2015) Insulin-like growth factors and related proteins in plasma and cerebrospinal fluids of HIV-positive individuals. J Neuroinflammation 12:72. CrossRef Medline

Takeshita S, Breen EC, Ivashchenko M, Nishanian PG, Kishimoto T, Vredevoe DL, Martinez-Maza O (1995) Induction of IL-6 and IL-10 production by recombinant HIV-1 envelope glycoprotein 41 (gp41) in the THP-1 human monocytic cell line. Cell Immunol 165:234-242. CrossRef Medline

Torten M, Franchini M, Barlough JE, George JW, Mozes E, Lutz H, Pedersen NC (1991) Progressive immune dysfunction in cats experimentally infected with feline immunodeficiency virus. J Virol 65: 2225-2230. Medline

Uddin S, Fish EN, Sher D, Gardziola C, Colamonici OR, Kellum M, Pitha PM, White MF, Platanias LC (1997) The IRS-pathway operates distinctively from the Stat-pathway in hematopoietic cells and transduces common and distinct signals during engagement of the insulin or interferon-alpha receptors. Blood 90:2574-2582. Medline

van Marle G, Antony JM, Silva C, Sullivan A, Power C (2005) Aberrant cortical neurogenesis in a pediatric neuroAIDS model: neurotrophic effects of growth hormone. AIDS 19:1781-1791. CrossRef Medline

Vergote D, Butler GS, Ooms M, Cox JH, Silva C, Hollenberg MD, Jhamandas JH, Overall CM, Power C (2006) Proteolytic processing of SDF-1alpha reveals a change in receptor specificity mediating HIV-associated neurodegeneration. Proc Natl Acad Sci U S A 103:19182-19187. CrossRef Medline

Vivithanaporn P, Heo G, Gamble J, Krentz HB, Hoke A, Gill MJ, Power C (2010) Neurologic disease burden in treated HIV/AIDS predicts survival: a population-based study. Neurology 75:1150-1158. CrossRef Medline

Walsh JG, Reinke SN, Mamik MK, McKenzie BA, Maingat F, Branton WG, Broadhurst DI, Power C (2014) Rapid inflammasome activation in microglia contributes to brain disease in HIV/AIDS. Retrovirology 11:35. CrossRef Medline

Yao H, Bethel-Brown C, Li CZ, Buch SJ (2010) HIV neuropathogenesis: a tight rope walk of innate immunity. J Neuroimmune Pharmacol 5:489 495. CrossRef Medline 